\title{
Gender differences in outcomes in people with schizophrenia in rural China: 14-year follow-up study
}

\author{
Mao-Sheng Ran, Wen-Jun Mao, Cecilia Lai-Wan Chan, Eric Yu-Hai Chen and Yeates Conwell
}

\section{Background}

Little is known about gender differences in the long-term outcomes of people with schizophrenia living in the community.

\section{Aims \\ To explore gender differences in the 14-year outcome of people with schizophrenia in rural China.}

\section{Method}

A 14-year follow-up study among a 1994 cohort $(n=510)$ of participants with schizophrenia was conducted in Xinjin County, Chengdu, China. All participants and their informants were followed up in 2004 and 2008 using the Patients Follow-up schedule.

\section{Results}

Compared with female participants, male participants were significantly younger, had significantly higher rates of mortality, suicide and homelessness, and poorer family and social support. There was no significant gender difference in Positive and Negative Syndrome Scale scores, previous suicide attempts, those never treated, previous hospital admission or inability to work. Longer duration of illness was associated with functional decline and comparatively poorer family economic status.

\section{Conclusions}

The long-term outcomes of men with schizophrenia is worse than those of women with the disorder in rural China. Higher mortality, suicide and homelessness rates in men may contribute partly to the higher prevalence of schizophrenia in women in China. Policies on social and family support and gender-specific intervention strategies for improving long-term outcomes should be developed for people with this disorder.

\section{Declaration of interest}

None.
Gender differences have been widely observed in the clinical presentation, psychosocial functioning and course of illness in people with first-episode and chronic schizophrenia. ${ }^{1,2}$ Genderrelated features of schizophrenia may be important for understanding its biological, psychological and sociological processes. ${ }^{3}$ However, long-term differences in outcomes between men and women with the disorder, especially those living in the community, are not clear. Evidence indicates that women have a more favourable prognosis (better psychosocial functioning, fewer readmissions to hospital, reduced negative symptoms and less disability) than men. ${ }^{4,5}$ Men with schizophrenia are found to have significantly higher levels of negative symptoms and marginally lower levels of functioning when baseline and follow-up time points are considered collectively. ${ }^{2}$ Differences in negative symptoms are found to mediate differences in functioning between male and female patients. However, the relationship between negative and positive symptoms and gender in the long-term outcomes of schizophrenia should be explored further. Beyond psychopathology, improved personal and social functioning are nowadays considered as important outcome measures. ${ }^{5,6}$ Evidence from a 2-year follow-up study indicates that men with schizophrenia display poorer working capacity and functional ability than women. ${ }^{7}$ Men experience more negative symptoms, which are particularly harmful to their role in society. However, it is not clear how these gender differences evolve in the long term, such as over 10 years.

Are the long-term outcomes of schizophrenia among people living in the community worse in men than women? Most previous studies on gender and schizophrenia are cross-sectional studies or involve short-term follow-up. ${ }^{4,5}$ There are few longterm follow-up studies of gender differences in outcomes of people with schizophrenia living in the community. ${ }^{2}$ We therefore conducted such a study with a large sample size, to examine the relationship between gender and symptoms, functioning and social support of people with schizophrenia. Our objectives were to explore gender differences in outcomes over 14 years of follow-up in Chengdu, China, and to test our research hypothesis that male participants with schizophrenia would have poorer long-term outcomes than female participants in a community setting.

\section{Method}

The sample of people with schizophrenia $(n=510)$ was identified from an epidemiological investigation of 123572 persons aged 15 years and older in six townships of Xinjin County in March 1994. Participants were identified through screening procedures for psychosis (face-to-face interviews with the head of each household together with the key informant method) and general psychiatric interview. The details of this investigation have been described in previous publications. ${ }^{8-10}$ All the participants lived in rural communities and met ICD-10 criteria for a diagnosis of schizophrenia, ${ }^{11}$ based on standardised administration of the Present State Examination (PSE-9) by trained research interviewers. ${ }^{12}$ Of the 1994 sample, $98.0 \%$ ( $n=500$ cases) were followed up 10 years later (May 2004) and 95.9\% ( $n=489$ cases) 14 years later (June 2008); participants and/or all their key informants were interviewed. The study was approved by the University of Guam's Committee on Human Research Subjects and all respondents gave informed consent at each stage of the study.

\section{Measurement}

The principal assessment tools were the PSE and the Social Disability Screening Schedule (SDSS) in the baseline investigation 
in $1994 .{ }^{8,9}$ The Positive and Negative Syndrome Scale (PANSS) and Global Assessment of Functioning (GAF) were additionally used in $2008 .{ }^{13,14}$ For participants alive at the visits in 2004 and 2008 at least one informant familiar with the person's life and circumstances as well as the person with schizophrenia was interviewed. Where the participant had died the next of kin or at least one person familiar with the participant was interviewed. All the interviews were conducted by trained psychiatrists using the Patients Follow-up Schedule (PFS) in 2004 and 2008. ${ }^{10}$ The PFS was used to collect information concerning demographic characteristics, causes and time of death, clinical symptoms, treatment information, criminal behaviour, social functioning and social support. For all participants, medical and psychiatric treatment records were obtained from hospital, village doctors' clinics and traditional healers. Where applicable, information from death certification and suicide notes was also obtained.

The classification of each death as due to suicide, accident or natural causes represented the consensus opinion of interviewers and independent researchers after reviewing all information obtained during the interviews. Participants were defined as homeless and lost to follow-up if informants reported that they had wandered and slept in public places and that their whereabouts at the time were unknown. Participants were defined as without caregiver if they had no one (family member or other) to provide care (e.g. food, housing, financial support or treatment). Family economic status was defined according to the average family income. Criminal behaviour (e.g. theft, physical or sexual assault and murder) was defined according to the reports of the participants and informants (such as relatives).

\section{Statistical analysis}

We explored the link between baseline assessment (1994) and later evaluations (2004 and 2008) for gender and other variables. The gender differences during the follow-up period (1994-2008) were assessed by comparing the demographic, psychological and social environment characteristics of male and female participants. A $\chi^{2}$-test or Fisher's exact test was used to assess the significance of the differences in categorical data, and $t$-tests (two-tailed) were used to compare between-group continuous factors. Statistical analyses were performed using SPSS version 20.0 for Windows.

\section{Results}

There were 510 persons with schizophrenia in 1994 who were included in this follow-up study. ${ }^{9,10}$ Of these, 10 were excluded in 2004 and 21 were excluded in 2008 because they were lost to follow up; therefore 500 participants $(98.0 \%)$ and 489 participants (95.9\%), respectively, were followed up in 2004 and 2008. Informants were available for all these individuals (100\%). In 2008 information on 300 participants was provided by both participant and informants, and information on 189 participants was provided by informants alone.

\section{Status of participants}

Table 1 shows the status of the participants in 2008. The rate of survival was significantly higher in women $(74.3 \%)$ than in men $(58.5 \%)(P<0.001)$. The rate of suicide was significantly higher in men $(7.1 \%)$ than in women $(3.0 \%)(P<0.05)$. There was no significant difference in deaths due to other causes between the genders. The rate of homelessness and loss to follow-up was significantly higher in men (11.2\%) than women $(5.7 \%)$ $(P<0.05)$.

\section{Gender differences}

Table 2 shows the different characteristics of male and female participants alive in 2008. Compared with the men, the women were significantly older and had more family members. There were no significant differences between the genders in previous physical illness, PANSS scores (positive and negative subscales and total score) and mean GAF score. Table 3 shows the gender differences among participants alive in 1994, 2004 and 2008. There were no significant differences between men and women in violent or criminal behaviour, previous suicide attempts, those never treated, previous hospital admission or inability to work. Compared with the men, women were significantly more likely to be married at all times, or bereaved in 1994 and 2008 . Compared with the women, men were significantly more likely to be divorced, live alone, have a lower family economic status and have no caregiver in 1994, 2004 or 2008. Table 3 also shows the changes in outcomes of participants who completed follow-up: compared with 1994, there was a significant increase in the rates of participants alive in 2008 (regardless of gender) who had poor family economic status $(P<0.01)$, violent or criminal behaviour $(P<0.001)$, previous suicide attempts $(P<0.001)$ and previous hospital admission $(P<0.001)$. The rate of inability to work had significantly increased in women $(P<0.001)$, but not in men $(P>0.1)$, in 2008 compared with 1994. Participants had a significant decrease in the rates of being without a caregiver $(P<0.001)$ and never having been treated $(P<0.05)$ in 2008 compared with 1994.

\section{Discussion}

To our knowledge, this is the first 14-year prospective cohort study exploring gender differences in the outcomes of people with schizophrenia in a rural community. It includes longitudinal follow-up and analyses based on time-dependent factors. The strengths of this study include the use of a large representative community sample in rural China, a longitudinal 14-year follow-up design and high rates of participant retention.

\section{Gender and outcomes}

Male participants with schizophrenia had a poorer long-term prognosis than their female counterparts, which is consistent with

\begin{tabular}{|c|c|c|c|}
\hline & $\begin{array}{l}\text { Men } \\
n(\%)\end{array}$ & $\begin{array}{l}\text { Women } \\
n(\%)\end{array}$ & Total \\
\hline Survival & $131(58.5)$ & $197(74.3)^{\star * *}$ & $328(67.1)$ \\
\hline \multicolumn{4}{|l|}{ Deaths } \\
\hline Suicide & $16(7.1)$ & $8(3.0)^{*}$ & $24(4.9)$ \\
\hline Other causes & $52(23.2)$ & $45(17.0)$ & $97(19.8)$ \\
\hline Homeless and lost to follow-up & $25(11.2)$ & $15(5.7)^{\star}$ & $40(8.2)$ \\
\hline Total & $224(45.8)$ & $265(54.2)$ & 489 (100.0) \\
\hline
\end{tabular}




\begin{tabular}{|c|c|c|c|c|c|}
\hline & $\begin{array}{c}\text { Men } \\
(n=131)\end{array}$ & $\begin{array}{l}\text { Women } \\
(n=197)\end{array}$ & $\chi^{2}$ or $t$ & d.f. & $P$ \\
\hline Living with offspring, n (\%) & $17(13.0)$ & $42(21.3)$ & $\chi^{2}=3.7$ & 1 & 0.05 \\
\hline Previous physical illness, $n$ (\%) & $52(39.7)$ & $61(31.0)$ & $\chi^{2}=2.6$ & 1 & 0.10 \\
\hline Age, years: mean (s.d.) & $53.4(12.6)$ & $57.8(12.7)$ & $t=3.11$ & 326 & 0.00 \\
\hline Education, years: mean (s.d.) & $5.1(3.2)$ & $4.3(3.2)$ & $t=2.28$ & 308 & 0.02 \\
\hline Age at onset, years: mean (s.d.) & $27.2(11.1)$ & $30.7(10.6)$ & $t=2.93$ & 326 & $<0.0001$ \\
\hline Number of family members: mean (s.d.) & $2.8(1.7)$ & $3.5(1.5)$ & $t=3.89$ & 320 & $<0.0001$ \\
\hline Duration of illness, years: mean (s.d.) & $24.7(11.0)$ & 25.9 (10.9) & $t=0.98$ & 314 & 0.33 \\
\hline \multicolumn{6}{|l|}{ Assessment scores: mean (s.d.) } \\
\hline PANSS positive symptoms & $11.8(5.6)$ & $12.4(6.2)$ & $t=0.85$ & 288 & 0.40 \\
\hline PANSS total score & $15.8(9.3)$ & $15.2(9.0)$ & $t=0.44$ & 222 & 0.66 \\
\hline PANSS negative symptoms & $54.8(20.0)$ & $56.9(22.8)$ & $t=0.65$ & 199 & 0.52 \\
\hline GAF & $61.5(24.5)$ & $61.5(24.9)$ & $t=0.01$ & 307 & 0.99 \\
\hline
\end{tabular}

previous studies in other countries. ${ }^{5,15}$ The International Pilot Study in a few countries also found female gender to be the best predictor of a remittent ( $v$. chronic) course of schizophrenia. ${ }^{16}$ The poor long-term prognosis for men in this study might be due to higher rates of suicide, homelessness, being single or divorced and without a caregiver, and to lower rates of survival and marriage. Given the high rate of violent and criminal behaviour in men with schizophrenia, ${ }^{17}$ they may more likely to be abandoned or rejected by their families and local community.

There are a number of possible reasons for better outcomes in women. Even though significant discrimination against women still exists, ${ }^{18}$ women with schizophrenia may have better support and care from their family or community. This may relate to our findings that female participants had significantly more family members than male participants, suggesting that women's deviant behaviour may be more readily tolerated than that of men in rural China, ${ }^{4,9,19}$ and may be less likely to alienate their families. Many women with the disorder continue to be able to perform some family functions (e.g. cooking, cleaning, washing and child care), but men with schizophrenia contribute little to smooth family functioning; moreover, their levels of violence will also be harder for family members to manage. ${ }^{17}$ Further, schizophrenia develops later in women, so their symptoms may not become apparent until after they are married; ${ }^{18}$ even if symptoms do appear women may still marry, given the high ratio of unmarried men to women in rural China (over 1.9). Also, given the lower social expectations for women, their domestic survival skills in the community are likely to be higher than those of men. ${ }^{18}$ Evidence indicates that oestrogen may facilitate the effects of antipsychotic medication, causing women to have a better treatment response than men and thus a better course of illness, ${ }^{21}$ and women have better premorbid functioning. ${ }^{4,5,18}$ However, more research is necessary in order to understand fully the relative contribution of gonadal hormones and other gender-specific developmental influences towards symptoms and functioning in psychosis. ${ }^{2}$

The rate of mortality (death, suicide) among men with schizophrenia is alarming. The high rate of suicide in male participants in this study is consistent with previous studies in developed countries. ${ }^{22}$ Homelessness is a serious problem among people with schizophrenia, especially men, which is also consistent with previous studies. ${ }^{10,19,23}$ Schizophrenia, which is diagnosed at roughly equal rates for men and women in Western countries, ${ }^{16,18}$ is diagnosed more frequently in women in China. ${ }^{9,24}$ We suggest that higher rates of mortality, suicide and homelessness in men with schizophrenia compared with women may contribute to the higher prevalence of the disorder in women in China. ${ }^{9,24}$

Compared with the cohort in 1994, even though more participants were treated in 2008 their status in this study worsened. For example, participants in 2008 had significantly higher rates of violent or criminal behaviour and previous suicide

Table 3 Outcomes of surviving participants in 1994, 2004 and 2008

\begin{tabular}{|c|c|c|c|c|c|c|}
\hline & \multicolumn{2}{|c|}{$1994(n=510)$} & \multicolumn{2}{|c|}{$2004(n=367)$} & \multicolumn{2}{|c|}{$2008(n=328)$} \\
\hline & $\begin{array}{c}\text { Men }(n=237) \\
n(\%)\end{array}$ & $\begin{array}{c}\text { Women }(n=273) \\
n(\%)\end{array}$ & $\begin{array}{c}\text { Men }(n=156) \\
n(\%)\end{array}$ & $\begin{array}{c}\text { Women }(n=211) \\
n(\%)\end{array}$ & $\begin{array}{c}\text { Men }(n=131) \\
n(\%)\end{array}$ & $\begin{array}{c}\text { Women }(n=197) \\
n(\%)\end{array}$ \\
\hline \multicolumn{7}{|l|}{ Marital status } \\
\hline Married & 105 (44.3) & $222(81.3)^{\star *}$ & $71(45.5)$ & $167(79.1)^{\star * *}$ & $59(45.0)$ & $150(76.1)^{\star * *}$ \\
\hline Single & $93(39.2)$ & $16(5.9)^{\star \star}$ & $51(32.7)$ & $6(2.8)^{\star \star \star}$ & $42(32.1)$ & $4(2.0)^{\star \star \star}$ \\
\hline Divorced & $29(12.2)$ & $5(1.8)^{* *}$ & $19(12.2)$ & $7(3.3)^{\star \star}$ & $19(14.5)$ & $8(4.1)^{\star \star}$ \\
\hline Bereaved & $10(4.2)$ & $30(11.0)^{*}$ & $15(9.6)$ & $31(14.7)$ & $11(8.4)$ & $35(17.8)^{*}$ \\
\hline Family economic status <mean & $143(60.3)$ & $135(49.5)^{*}$ & $97(62.2)$ & $108(51.2)^{*}$ & $96(73.3)$ & $137(69.5)$ \\
\hline Living alone & $51(21.5)$ & $13(4.8)^{\star * *}$ & $44(28.2)$ & $21(10.0)^{\star \star *}$ & $35(26.7)$ & $14(7.1)^{\star * *}$ \\
\hline Without caregiver & 65 (27.4) & $25(9.2)^{\star *}$ & $25(16.0)$ & $11(5.2)^{\star *}$ & $15(11.5)$ & $5(2.5)^{* *}$ \\
\hline Violent or criminal behaviour & $7(3.0)$ & $11(4.0)$ & NR & NR & $26(19.8)$ & $30(15.2)$ \\
\hline Previous suicide attempt & $14(5.9)$ & $23(8.4)$ & $26(16.7)$ & $35(16.6)$ & $28(21.4)$ & $41(20.8)$ \\
\hline Never treated & $81(34.2)$ & $75(27.5)$ & $37(23.7)$ & $52(24.6)$ & $29(22.1)$ & $38(19.3)$ \\
\hline Previous hospital admission & $56(23.6)$ & $54(19.8)$ & $59(37.8)$ & $61(28.9)$ & $50(38.2)$ & $70(35.5)$ \\
\hline Inability to work & $51(21.5)$ & $46(16.8)$ & $34(21.8)$ & $50(23.7)$ & $37(28.2)$ & $57(28.9)$ \\
\hline
\end{tabular}


attempts than in 1994. Female participants had a significantly higher rate of inability to work in 2008 than in 1994. Although the average net income of each farmer in Xinjin County had increased from 1994 to 2008, all participants' family economic status had relatively worsened in 2008 compared with that in 1994. Evidence from higher-income countries indicates that people with schizophrenia may decline to less favourable socioeconomic status over the course of the illness, ${ }^{25}$ and this is confirmed by our study. Such socioeconomic factors may have an important role in influencing long-term outcomes of people with schizophrenia. Further studies should be conducted to explore the impact of socioeconomic development on the outcomes of this group.

\section{Gender and other characteristics}

What factors are important in influencing the long-term outcomes of people with schizophrenia? Evidence indicates that nevertreated individuals with schizophrenia might have a poorer outcome (e.g. higher mortality) than those accepting treatment with antipsychotic drugs. ${ }^{19,26}$ In a 15-year and 25-year international follow-up study a significant proportion of treated incident cases of schizophrenia achieved a favourable long-term outcome. ${ }^{27}$ Our study showed no significant difference between men and women in the proportion who never received treatment for their illness in 1994, 2004 or 2008. There was also no significant difference between male and female participants in the proportion who had one or more previous hospital admissions, consistent with studies in higher-income countries. ${ }^{28}$

Evidence indicates that later age at onset may be also associated with better outcome in schizophrenia and other psychoses. ${ }^{29}$ Consistent with published research, ${ }^{5,30}$ we found female participants who survived through 14 years of follow-up to have a later age at onset (women 30.7 years, men 27.2 years) and better outcomes than male participants at that point in follow-up. An early onset of schizophrenia might arrest social development, resulting in greater social impairment in boys than in girls. ${ }^{4,18}$ However, even though women had a more favourable outcome profile in cases of young or middle-age onset, they tended to have a poorer outcome in the very late-onset cases, particularly in terms of course, longest episode and remission. ${ }^{30}$ The 'oestrogen hypothesis' suggests that the disorder only becomes apparent after menopause for a proportion of women who have a psychosis liability. ${ }^{31}$ Consequently, men with lower levels of vulnerability develop psychotic disorders in old age and may display better outcomes than their female counterparts. ${ }^{30}$ Further studies will be needed to examine the effect of gender-age interactions.

The link between negative symptoms and functioning has been well established in research studies examining outcomes in patients with chronic schizophrenia. ${ }^{32,33}$ Differences in negative symptoms were found to mediate differences in functioning between men and women. ${ }^{2}$ Although women with schizophrenia might have fewer negative symptoms than men, ${ }^{5}$ we found no significant difference in positive and negative symptoms between men and women who completed 14 years follow-up, which is consistent with a previous study. ${ }^{4}$ It may be that men with severe positive and negative symptoms are more likely to die earlier or be lost to follow-up. Further studies need to be conducted on gender and long-term symptoms.

Previous studies in high-income countries indicate that women with schizophrenia may have better psychosocial functioning or be more skilled and less disabled than men. ${ }^{4,34}$ However, the results of our study indicated that there was no difference in long-term social functioning (e.g. GAF score, inability to work) between the genders. Our results also showed that significantly more female participants were unable to work after 14 years (2008 v. 1994), which indicates higher rates of disability and poor long-term social functioning. Our study indicates that the trend of social functioning in people with schizophrenia, especially women, may be on a downhill path. ${ }^{35}$ Given the higher rates of suicide and mortality in men with schizophrenia in this study, women with more severe illness might survive longer into the follow-up period which might also result in different mixes of illness severity over time. Further investigations should explore the factors that influence the course of social disability, which is meaningful for planning rehabilitation interventions.

Although our previous study in China showed that male participants had significantly higher rates of all forms of criminal behaviour $(13.8 \%)$ than female participants $(6.8 \%)(P<0.05),{ }^{17}$ in 2008 we found no significant gender difference in rates of violent and criminal behaviour, which is consistent with some previous international studies. ${ }^{36,37}$ This study showed that violent behaviour was also common among female participants in rural China. Previous violent behaviour was found to be a predictor of criminal behaviour in people with schizophrenia. ${ }^{17}$

Sociocultural conditions appear to modify the long-term course of schizophrenia. ${ }^{27}$ In rural China we found that men with the disorder had higher rates of divorce and living alone, lower family economic level and fewer caregivers. Compared with men, women with schizophrenia might be more likely to be accepted by families and communities in this setting, which is vital to patients' survival and integration in the community. Stronger social and familial acceptance for women may serve to reduce their stress more effectively. Poor family and social support for men may be risk factors for their poor long-term prognosis. This is consistent with a previous study in which men reported less positive social support than their female counterparts and felt they received marginally more criticism than women. ${ }^{2}$ Although people with mental illness generally are not confined to institutions in high-income countries, this does not guarantee that they will be fully integrated into their communities owing to the disabilities produced by their illness and also to stigmatising and discriminatory public attitudes. ${ }^{38}$ The quality of social networks around an individual patient has been shown to correlate with that person's level of functioning. ${ }^{39}$ Family involvement, support and warmth may predict improvement in negative symptoms and social functioning. ${ }^{40}$ In general, China developed rapidly between 1994 and 2008. However, in our study no improvement was apparent in family or social support for the participants or in family economic status in rural Xinjin County. Further studies should be conducted to explore the relationship between social development and mental healthcare (e.g. family, community and social care) for people with schizophrenia in the community.

\section{Limitations of the study}

The limitations of this study include possible recall bias for interviews with participants and informants at long-term follow-up intervals, but such bias may be minimised by the use of multiple follow-up data sources. The death and suicide rates may be underestimated because most homeless individuals were lost to follow-up. Over the 14 years much has changed in China, including access to and the nature of the treatments received, access to other services and quality of life more generally. Findings here may not apply to other settings in which such changes have not been observed. Given the diversity of sociocultural, economic and care provision characteristics, results from rural China may not generalise to high-income countries. 


\section{Implications for services}

Even though significant discrimination against women still exists in rural China, women with schizophrenia have better support and care from family or community, which contributes to their better long-term outcomes. Men with the disorder have higher rates of mortality, suicide and homelessness than women, which contribute partly to the higher prevalence of schizophrenia in women than in men in China. Our results have implications for improving long-term prognosis of patients with schizophrenia in China and elsewhere. The characteristics of both men and women with schizophrenia should be taken into account when developing interventions to enhance their long-term prognosis. Compared with female patients, male patients in rural China comprise a highly vulnerable subgroup of individuals who, in addition to psychiatric care, need more support from family, community and society on a long-term basis. We suggest that early treatment (e.g. antipsychotic medication and other interventions) and community-based care and support (e.g. family, community and social level) are crucial for improving the long-term outcomes of both men and women with schizophrenia. ${ }^{27,41}$ Given that few programmes address psychosis in rural China from the standpoint of gender, gender-specific interventions should be provided for patients with schizophrenia. ${ }^{42}$ For example, for men care should focus on medication, preventing suicide and violent behaviour and providing family and social support. For women, improving medication and social functioning should have greater emphasis. In the Chinese context, support for the patient's family should also be strengthened.

Given the representative sample used in this study, we are confident that our findings are generalisable to the population of people with schizophrenia in rural areas, and even to other low- and middle-income countries that have a similar social environment. Overall long-term outcomes of schizophrenia are a major concern in psychiatry. It is crucial to supply comprehensive community mental health services and medication to these people in rural China. The impact of socioeconomic development on outcomes for men and women with schizophrenia living in the community should be investigated further.

Mao-Sheng Ran, MMed, PhD, Department of Social Work and Social Administration, University of Hong Kong; Wen-Jun Mao, MD, Chengdu Mental Health Centre, Chengdu, China; Cecilia Lai-Wan Chan, PhD, Department of Social Work and Social Administration, Eric Yu-Hai Chen, MD, Department of Psychiatry, University of Hong Kong, Hong Kong; Yeates Conwell, MD, Department of Psychiatry, University of Kong, Hong Kong; Yeates Conwell, MD, Department
Rochester Medical Center, Rochester, New York, USA

Correspondence: Dr Mao-Sheng Ran, Department of Social Work and Social Administration, Faculty of Social Sciences, University of Hong Kong, Hong Kong. Email: msran@hku.hk.

First received 2 Oct 2014, final revision 26 Aug 2014, accepted 11 Sep 2014\#\#

\section{Funding}

The 1994 Chengdu study was supported by a grant from the China Medical Board in New York (CMB, 92-557; M.Z.X.). This study was supported in part by National Institutes of Health (NIH) GRIP 1 R01 TW007260-01 (M.S.R.) from the Fogarty International Center, $\mathrm{NIH}$ and the American Foundation for Suicide Prevention (M.S.R.)

\section{Acknowledgements}

The authors thank Chengdu Mental Health Centre and Xinjin Mental Hospital for collaboration and data collection.

\section{References}

1 Usall J, Ochoa S, Araya S, Marquez M. Gender differences and outcome in schizophrenia: a 2-year follow-up study in a large community sample. Eur Psychiatry 2003; 18: 282-4.
2 Willhite RK, Niendam TA, Bearden CE, Zinberg J, O'Brien MP, Cannon TD. Gender differences in symptoms, functioning and social support in patients at ultra-high risk for developing a psychotic disorder. Schizophr Res 2008; 104: 237-45.

3 Castle DJ, Abel K, Takei N, Murray RM. Gender differences in schizophrenia: hormonal effect or subtypes? Schizophr Bull 1995; 21: 1-12.

4 Mueser KT, Bellack AS, Morrison RL, Wade JH. Gender, social competence, and symptomatology in schizophrenia: a longitudinal analysis. J Abnorm Psychol 1990; 99: 138-47.

5 Leung A, Chue P. Sex differences in schizophrenia, a review of the literature. Acta Psychiatr Scand Suppl 2000; 401: 3-38.

6 Burns T, Patrick D. Social functioning as an outcome measure in schizophrenia studies. Acta Psychiatr Scand 2007; 116: 403-18.

7 Salokangas RKR, Stengard E. Gender and short-term outcome in schizophrenia. Schizophr Res 1990; 3: 333-45.

8 Ran MS, Xiang MZ, Huang MS, Shan YH. Natural course of schizophrenia: 2-year follow-up study in a rural Chinese community. Br J Psychiatry 2001; 178: $154-8$.

9 Ran MS, Xiang MZ, Li SX, Shan YH, Huang MS, Li SG, et al. Prevalence and outcome of schizophrenia in a Chinese rural area: an epidemiological study. Aust N Z J Psychiatry 2003; 37: 452-7.

10 Ran MS, Chen EYH, Conwell Y, Chan CL, Yip PS, Xiang MZ, et al. Mortality in people with schizophrenia in rural China: 10-year cohort study. Br J Psychiatry 2007; 190: 237-42.

11 World Health Organization. The ICD-10 Classification of Mental and Behavioural Disorders: Clinical Descriptions and Diagnostic Guidelines. WHO, 1992.

12 Wing JK, Cooper JE, Sartorius N. The Measurement and Classification of Psychiatric Symptoms. Cambridge University Press, 1974.

13 Kay SR, Fiszbein A, Opler A. The Positive and Negative Syndrome Scale (PANSS) for schizophrenia. Schizophr Bull 1987; 13: 261-76.

14 American Psychiatric Association. Diagnostic and Statistical Manual of Mental Disorders (4th edn, text revision) (DSM-IV-TR). APA, 2000.

15 Tamminga CA. Gender and schizophrenia. J Clin Psychiatry 1997; 58: 33-7.

16 Sartorius N, Jablensky A, Korten G, Ernberg G, Anker M, Cooper JE, et al. Early manifestations and first contact incidence of schizophrenia in different cultures. Psychol Med 1986; 16: 909-28.

17 Ran MS, Chen PY, Liao ZG, Chan CLW, Chen EYH, Tang CP, et al. Criminal behavior among persons with schizophrenia in rural China. Schizophr Res 2010; 122: 213-8

18 Pearson V. Goods on which one loses: women and mental health in China Soc Sci Med 1995; 41: 1159-73.

19 Ran MS, Chan CL, Chen EY, Mao WJ, Hu SH, Tang CP, et al. Differences in mortality and suicidal behavior between treated and never-treated people with schizophrenia in rural China. Br J Psychiatry 2009; 195: 126-31.

20 Zhou XD, Wang XL, Li L, Hesketh $\mathrm{T}$. The very high sex ratio in rural China: impact on the psychosocial wellbeing of unmarried men. Soc Sci Med 2011; 73: $1422-7$

21 Goldstein JM, Cohen LS, Horton NJ, Lee H, Andersen S, Tohen M, et al. Sex differences in clinical response to olanzapine compared with haloperidol. Psychiatry Res 2002; 110: 27-37.

22 Lester D. Sex differences in completed suicide by schizophrenic patients: a meta-analysis. Suicide Life Threat Behav 2006; 36: 50-6.

23 Folsom DP, Hawthorne W, Lindamer L, Gilmer T, Bailey A, Golshan S, et al. Prevalence and risk factors for homelessness and utilization of mental health services among 10,340 patients with serious mental illness in a large public mental health system. Am J Psychiatry 2005; 162: 370-6.

24 Phillips MR, Yang GH, Li SR, Li Y. Suicide and the unique prevalence pattern of schizophrenia in mainland China: a retrospective observational study. Lancet 2004; 364: 1062-8.

25 Hudson CG. Socioeconomic status and mental illness: test of the social causation and selection hypotheses. Am J Orthopsychiatry 2005; 75: 3-18.

26 Tiihonen J, Lonnqvist J, Wahlbeck K, Klaukka T, Niskanen L, Tanskanen A, et al. 11-year follow-up of mortality in patients with schizophrenia: a population-based cohort study (FIN11 study). Lancet 2009; 374: 620-7.

27 Harrison G, Hopper K, Craig T, Laska E, Siegel C, Wanderling J, et al. Recovery from psychotic illness: a 15- and 25-year international follow-up study. Br J Psychiatry 2001; 178: 506-17.

28 McAlpine D, Mechanic D. Utilization of specialty mental health care among persons with severe mental illness: the roles of demographics, need, insurance, and risk. Health Serv Res 2000; 35: 277-92.

29 Rabinowitz J, Levine SZ, Hafner H. A population based elaboration of the role of age of onset on the course of schizophrenia. Schizophr Res 2006; 88: 96-101. 
30 Kohler S, van der Werf M, Hart B, Morrison G, Mccreadie R, Kirkpatrick B, et al. Evidence that better outcome of psychosis in women is reversed with increasing age of onset: a population-based 5-year follow-up study. Schizophr Res 2009; 113: 226-32.

31 Seeman MV, Lang M. The role of estrogens in schizophrenia gender differences. Schizophr Bull 1990; 16: 185-94.

32 Breier A, Schreiber JL, Dyer J, Pickar D. National Institute of Mental Health longitudinal study of chronic schizophrenia: prognosis and predictors of outcome. Arch Gen Psychiatry 1991; 48: 239-46.

33 Bottlender R, Strauss A, Moller HJ. Social disability in schizophrenic, schizoaffective and affective disorders 15 years after first admission. Schizophr Res 2010; 116: 9-15.

34 Grossman LS, Harrow M, Rosen C, Faull R. Sex difference in outcome and recovery for schizophrenia and other psychotic and nonpsychotic disorders. Psychiatric Serv 2006; 57: 844-50

35 Ganev K. Long-term trends of symptoms and disability in schizophrenia and related disorders. Soc Psychiatry Psychiatr Epidemiol 2000; 35: 389-95.

36 Swanson JW, Swartz MS, Van Dorn RA, Elbogen EB, Wagner HR, Rosenheck RA, et al. A national study of violent behavior in persons with schizophrenia. Arch Gen Psychiatry 2006; 63: 490-9.
37 Walsh E, Gilvarry C, Samele C, Harvey K, Manley C, Tattan T, et al. Predicting violence in schizophrenia: a prospective study. Schizophr Res 2004; 67: 247-52.

38 Leff J, Warner R. Social Inclusion of People With Mental Illness. Cambridge University Press, 2006

39 Erickson DH, Beiser M, lacono WG. Social support predicts 5-year outcome in first-episode schizophrenia. J Abnorm Psychol 1998; 107: 681-5.

40 O'Brien MP, Gordan JL, Bearden CE, Lopez SR, Kopelowicz A, Cannon TD. Positive family environment predicts improvement in symptoms and social functioning among adolescents at imminent risk for onset of psychosis. Schizophr Res 2006; 81: 269-75.

41 Ran MS, Xiang MZ, Chan CLW, Leff J, Simpson P, Huang MS, et al. Effectiveness of psychoeducational intervention for rural Chinese families experiencing schizophrenia: a randomised controlled trial. Soc Psychiatry Psychiatr Epidemiol 2003; 38: 69-75.

42 Koster A, Lajer M, Lindhardt A, Rosenbaum B. Gender differences in firs episode psychosis. Soc Psychiatry Psychiatr Epidemiol 2008; 43: 940-6.

\section{poems by doctors}

\section{These are the Stories Doctors Tell}

\section{Jonathan Knight}

These are the stories doctors tell:

The Christmas gift, the troubled gaze,

The cognitive decline of age,

The family rift, the loss of sight,

The ones who lived, and those who might,

The dying and the worried well;

These are the stories doctors tell.

And these are the patients doctors know: The tired and anxious, the slow, the lame

The ones that never go away,

The bright, the angry malcontent,

The addict and the one that's sent

The garrulous, and those brought low;

These are the patients doctors know.

And these are the moments doctors fear: The unexplained, the shadowed lung,

The relative who asks: "How long?"

The purple rash, traumatic birth,

The contemplation of our worth:

Examinations that draw near

These are the moments doctors fear.

And these are the journeys doctors make: The drone of dusty lecture halls,

The teaching round, the nights on-call;

Uncertainties and things un-said,

The visit to the hospice bed.

That one mistake. That touch of grace.

These are the journeys doctors make.

Jonathan Knight works as a general practitioner in Ipswich and co-organises an annual reflective writing workshop for GPS. The poem was selected by Femi Oyebode.

Published in The Hippocrates Prize Anthology (Commended Poem, NHS category), Hippocrates Press, 2012.

(c) Jonathan Knight. Reprinted with permission. 